\title{
Comparison between traffic light models for a road mesh in Manaus using SUMO
}

\author{
Jhordan Oliveira de Vasconcelos Dias', Moisés Pereira Bastos ${ }^{2}$, Kattylinne de Melo Barbosa ${ }^{3}$ \\ 1,2,3, Escola Superior de Tecnologia da Universidade do Estado do Amazonas Av. Darcy Vargas, 1200, Parque 10 de Novembro. - \\ Manaus - Amazonas - Brasil. CEP 69050-020, +55 (92) 3878-4301 \\ Email: jhordan.dias@gmail.com; mpbastos@uea.edu.br; kdbarbosa@uea.edu.br
}

Received: June $12^{\text {th }}, 2017$

Accepted: September 25th, 2017

Published: September 30th, 2017

Copyright $\odot 2016$ by authors and Institute of Technology Galileo of Amazon (ITEGAM). This work is licensed under the Creative Commons Attribution International License (CC BY 4.0).

http://creativecommons.org/licenses/by/4.0/ (c) (i) (3) Open Acten:

\begin{abstract}
This work aims to make a comparison between types of traffic lights control for the Mario Ypiranga Monteiro avenue in Manaus using the traffic simulation software SUMO. The avenue has a very high flow of vehicles and the intervention proposed by the project aims to improve traffic in the region through the implementation of flexible traffic light progression. The road mesh was built in the simulator, with the data provided by the Municipal Institute of Traffic Engineering and Surveillance, a serie of simulations were made until finding the appropriate parameters and tabulating the performance data of the different strategies. Analyzing the simulations and tabulated data, it can be seen a significant advantage using traffic signal progression to the road mesh.
\end{abstract}

Keywords: traffic light control, traffic simulation, SUMO, flow of vehicles, flexible traffic light progression.

\section{Comparativo entre modelos de progressão semafórica para uma malha viária de Manaus utilizando SUMO}

RESUMO

Este trabalho tem como objetivo fazer um comparativo entre tipos de controle semafórico para a Avenida Mario Ypiranga Monteiro na cidade de Manaus utilizando o software de simulação de trânsito SUMO. A avenida possui um fluxo de veículos muito elevado e a intervenção proposta pelo projeto visa melhorar o trânsito na região por meio da implantação da progressão semafórica flexível. A malha viária foi montada no simulador e com os dados fornecidos pelo Instituto Municipal de Engenharia e Fiscalização do Trânsito, foram feitas uma série de simulações até encontrar os parâmetros adequados e tabular os dados de desempenho das diferentes estratégias. Analisando tanto as simulações como os dados tabulados, pode-se perceber uma significativa vantagem do uso da progressão semafórica para essa malha viária.

Palavras-chave: Controle semafórico, simulação de trânsito, SUMO, fluxo de veículos, progressão semafórica flexível.

\section{INTRODUÇÃO}

Ao longo dos anos, com o aumento populacional e popularização do carro como meio de transporte acarretaram uma série de problemas comuns aos centros urbanos como por exemplo poluição, logística, excesso de veículos e consequentemente congestionamentos. Esses problemas vêm se intensificando, pois, a frota de veículos aumenta a cada dia enquanto que estratégias de trânsito e infraestrutura viária não sofrem grandes alterações [1].
A cidade de Manaus, capital do estado do Amazonas, não é diferente, os investimentos em infraestrutura viária não acompanham o crescimento da frota de veículos.

Um estudo realizado em 2011 pela Secretaria de Estado e Desenvolvimento Econômico (SEPLAN) revela que as perdas geradas com as contínuas retenções no tráfego da cidade 
equivalem a um custo de $\mathrm{R} \$ 530$ milhões/ano, considerando variáveis como o tempo gasto no congestionamento, custos de oportunidade de mão-de-obra e custos financeiros [2]. Os congestionamentos afetam também a qualidade de vida da população pois causa atraso no deslocamento das pessoas, estresse e desconforto por horas, contribui para a poluição do ar devido ao consumo excessivo de combustível, além da poluição sonora causada pela buzina dos veículos e os motores funcionando.

A eficiência do planejamento e gerenciamento do tráfego exige o uso de ferramentas computacionais que possam simular a viabilidade de medidas que provoquem impacto no trânsito, de forma adequada e consistente. Dessa forma é possível corrigir e otimizar propostas de intervenção no tráfego sem a necessidade de implementação física, o que evitaria transtornos e gastos de se implantar medidas não testadas [3].

$\mathrm{O}$ estudo apresentado neste trabalho faz parte de um programa denominado PAIC (Projeto de Apoio à Iniciação Científica) da UEA (Universidade do Estado do Amazonas) fomentado pela FAPEAM (Fundação de Amparo à Pesquisa do Estado do Amazonas) com o tema: Proposta de implementação de Controle Semafórico de Tempo Fixo e Atuado pelo Tráfego em Rede para a Avenida Mario Ypiranga Monteiro. O projeto possui o objetivo de desenvolver um sistema de controle semafórico centralizado de tempo fixo e atuado pelo tráfego para uma determinada malha viária de Manaus.

\section{REVISÃO BIBLIOGRÁFICA}

\section{II.1 SINALIZAÇÃO SEMAFÓRICA}

Segundo o Manual Brasileiro de Sinalização de Trânsito Volume V (2012) a sinalização semafórica possui o objetivo de transmitir aos usuários a informação sobre o direito de passagem em interseções e/ou seções de via onde o espaço viário é disputado por dois ou mais movimentos conflitantes, ou advertir sobre a presença de situações na via que possam comprometer a segurança dos usuários.

Existem duas estratégias de controle semafórico: isolado e em rede. No primeiro cada interseção é controlada independente das demais levando em conta somente a demanda do tráfego naquela interseção. Enquanto que no controle em rede, que também é conhecido como coordenação semafórica, é considerado o desempenho de um conjunto de cruzamentos, visando melhorar o fluxo de veículos em uma via ou em uma rede fechada [4].

A sinalização pode aumentar no número de paradas dos veículos, contribuir para a formação de filas, aumentar o tempo de percurso e reduzir a velocidade média nas vias, principalmente no caso de malhas viárias compostas por diversas interseções semaforizadas relativamente próximas umas das outras. Nessas situações o controle semafórico em rede é fundamental para garantir a fluidez do tráfego e bom funcionamento da malha viária [5].

Segundo o Manual de Semáforos do [4] existem três tipos principais de coordenação semafórica: simultâneo, alternado e progressivo. No simultâneo todos os sinais abrem e fecham no mesmo instante de tempo. Possui a desvantagem de incentivar os motoristas a aumentar a velocidade para poder passar em um número maior de cruzamentos sem parar. No alternado os semáforos adjacentes mostram indicações contrárias de modo que se o motorista mantiver uma velocidade compatível com a via, ele não irá parar nas interseções. Esse método funciona bem apenas em vias que possuam cruzamentos equidistantes. $\mathrm{Na}$ progressão os tempos de verde entre os cruzamentos adjacentes são ajustados de forma a se obter uma progressão ao longo da via para uma determinada velocidade.

\section{II.2 PROGRESSÃO SEMAFÓRICA}

Segundo [4][7-9] existem três abordagens distintas para a progressão semafórica de acordo com as condições de tráfego: 1 - A maximização da largura de banda de verde, por meio da definição da defasagem entre os semáforos consecutivos que permite que um pelotão de veículos se movimente ao longo de uma via arterial com velocidade constante ao encontrar todos os semáforos verdes, sendo conhecido como onda verde. 2 - A minimização dos atrasos e paradas, por meio da definição dos instantes de abertura de cada semáforo que impeça que os veículos reduzam a velocidade ou até parem em uma interseção semaforizada posterior. 3 - A combinação sequencial ou simultânea das outras duas abordagens, de modo a obter as vantagens de ambos. A progressão semafórica proposta nesse trabalho utiliza a abordagem três.

A onda verde é uma técnica de coordenação semafórica que visa melhorar o fluxo de veículos em uma via arterial que possui interseções semaforizadas consecutivas. Nessa técnica há a maximização da banda de passagem, onde ocorre os ajustes dos tempos de abertura de cada semáforo de forma a permitir a passagem de um pelotão por toda a via com uma certa velocidade de progressão sem parar em nenhum sinal vermelho, desse modo há a redução do tempo de viagem, evita a formação de filas ou retardando o aumento delas, redução do número de acidentes e a imprudência dos condutores [8][9].

A técnica manual de progressão flexível mais conhecida e utilizada em cidades brasileiras para coordenar semáforos é o Diagrama Espaço-Tempo. Foi desenvolvido entre as décadas de 1930 e 1940 e é utilizado um procedimento gráfico de tentativa e erro, para definir as bandas verdes e as defasagens semafóricas do sistema de progressão. Este método de coordenação permite que o engenheiro de tráfego visualize previamente a largura da banda verde disponível, além de a progressão também ser facilmente percebida pelos motoristas. No entanto, o procedimento mostra-se bastante trabalhoso para a coordenação de várias interseções, especialmente em vias de duplo sentido ou redes mais complexas [10]. Se esse método for combinado com uma boa modelagem do tráfego, para que se possa simular eficientemente o seu comportamento, é possível de obter uma excelente coordenação semafórica.

\section{II.3 SUMO}

O SUMO (Simulator of Urban Mobility) é um software de simulação free, opensource, desenvolvido em $\mathrm{C}++$ pelo Instituto de Pesquisas em Transporte do Centro Aeroespacial Alemão (DLR) em parceria com Centro de Informática Aplicada de Colônia. Ele foi criado com o objetivo de ser uma plataforma para testes de novos produtos e soluções aplicada à modelagem de trânsito e tem grande aceitação na comunidade de simulação microscópica e mesoscópica de engenharia de tráfego [1]. 
Por ser utilizado para fins de pesquisa, o SUMO segue três princípios básicos: pouco consumo de memória, facilidade em estender a aplicação e velocidade nas simulações. A sua utilização se dá através de linhas de comando, a configuração da malha viária e de outros parâmetros de simulação utilizam essas linhas de comando. A entrada e saída de dados ocorrem diretamente por arquivos XML. O software foi dividido em várias partes, cada uma com uma função e são executadas separadamente, de modo que o usuário passe por diversas etapas até a simulação final [11]. Por esses motivos o SUMO foi o simulador escolhido para o projeto.

Para criar a malha viária que será utilizada na simulação é necessário declarar as informações em arquivos XML, e com a ferramenta NETCONVERT que acompanha o software, é gerado um outro arquivo XML que contém todas as informações necessárias para iniciar a simulação. Os arquivos são separados de acordo com as informações que possuem, neste projeto foram utilizados os seguintes arquivos:

- Nodes: São definidos todos os pontos e interseções que a malha viária possui, além de definir quais interseções são semaforizadas.

- Edges: São definidas as arestas que ligam os pontos, eles correspondem as vias em um único sentido.

- Types: São definidos os tipos de vias possíveis, com o número de faixas e a velocidade máxima.

- Connection: São definidas as conexões entre as vias que se deseja ter, pois em princípio são permitidas todas as conversões possíveis.

- Traffic Light Logic: São definidas as fases, duração de cada fase e defasagem de todos os semáforos que se deseja utilizar na simulação, pois já é gerada uma programação semafórica padrão.

-Routes: São definidos os tipos de veículos com as suas configurações, como aceleração, velocidade máxima e cor, as rotas possíveis obedecendo os sentidos das vias, além do fluxo de veículos com o número de veículos por hora.

\section{MATERIAIS E MÉTODOS}

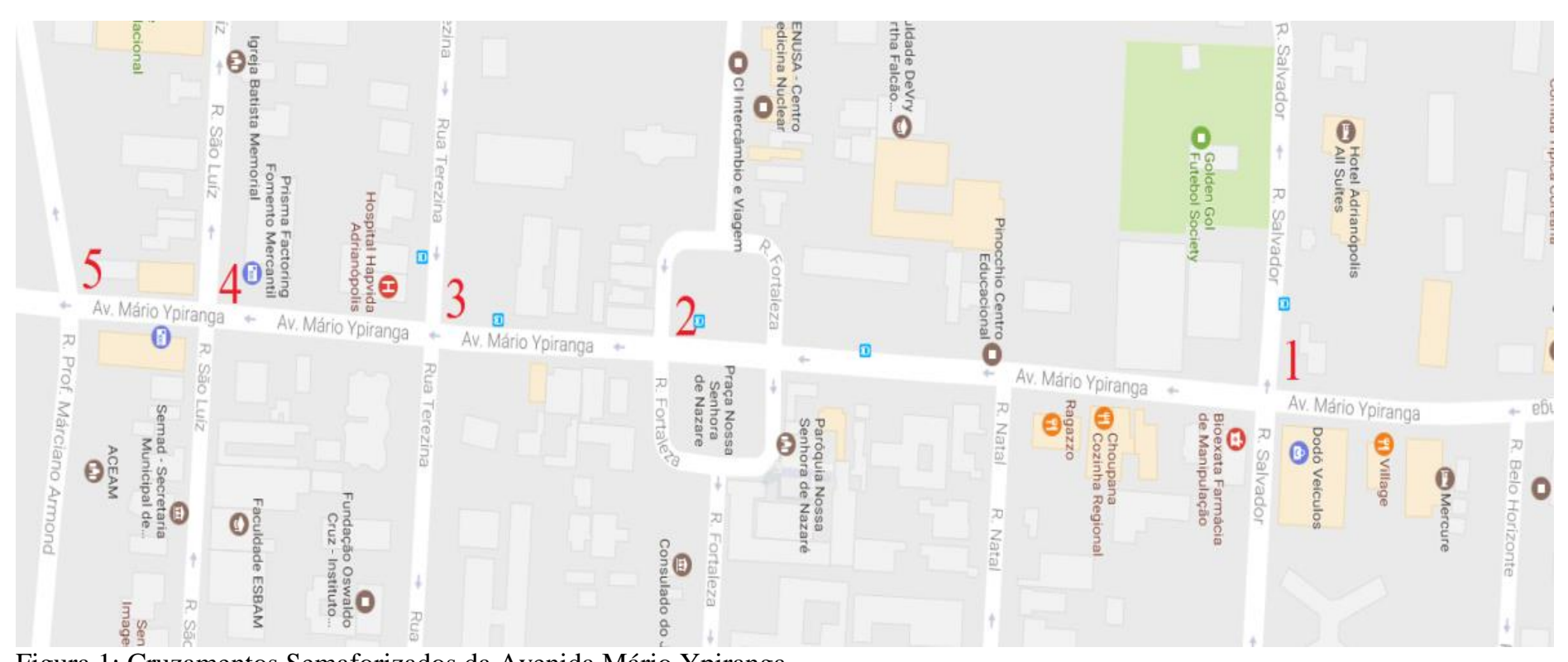

Figura 1: Cruzamentos Semaforizados da Avenida Mário Ypiranga.

Fonte: Autores, (2017).
Para a definição do controle semafórico proposto nesse trabalho foi considerada uma malha viária que possui um grande congestionamento devido ao alto fluxo de veículos e a presença de interseções semaforizadas. Em seguida foi feito o levantamento e revisão bibliográfica sobre controle semafórico e simulação de trânsito, e com as conclusões obtidas nos estudos pôde se escolher a estratégia utilizada para a progressão semafórica. Foi montada a malha viária no software e foram feitas inúmeras simulações para avaliar o comportamento da mesma, sendo então encontrados os valores adequados para os parâmetros da progressão semafórica. Além disso para validar o controle proposto foram feitas simulações com duas variações da onda verde para a malha viária com o objetivo de comparar resultados entre elas.

\section{III.1 MALHA VIÁRIA}

A malha viária escolhida foi da Avenida Mário Ypiranga Monteiro, no bairro Adrianópolis, zona Centro-Sul de Manaus, devido ser uma via de grande importância para o deslocamento urbano da cidade. A Avenida possui uma extensão total de aproximadamente $5 \mathrm{~km}$ sendo uma das principais ligações entre as zonas Centro-Sul e Sul da cidade, passando por vários bairros até chegar a zona central. Com isso, inúmeras vias convergem o seu fluxo de veículos para a via supracitada, além de conter um dos principais shoppings e o maior pronto socorro da capital amazonense. $O$ trecho de aproximadamente $1 \mathrm{~km}$ mostrado na figura 1 é o trecho de maior gargalo, pois possui cinco interseções semaforizadas:

1. Cruzamento da Avenida Mário Ypiranga com a Rua Salvador.

2. Cruzamento da Avenida Mário Ypiranga com a Rua Fortaleza.

3. Cruzamento da Avenida Mário Ypiranga com a Rua Terezina.

4. Cruzamento da Avenida Mário Ypiranga com a Rua São Luiz.

5. Cruzamento da Avenida Mário Ypiranga com a Rua Professor Marciano Armond. 
Para realizar o controle semafórico da malha viária é necessário conhecer seu comportamento e funcionamento atual. Foram então solicitados os dados do fluxo de veículos dos cruzamentos do trecho em estudo ao Instituto Municipal de Engenharia e Fiscalização do Trânsito (Manaustrans) que forneceu os dados dos cruzamentos 1 e 5, coletados em 2013 e 2015, respectivamente. Foi feito então o cálculo para estimar o fluxo de veículos para o ano de 2017 e os valores foram inseridos no arquivo Routes do SUMO. As figuras 2 e 3 mostram o diagrama de movimentos e estágios dos cruzamentos 1 e 5, respectivamente, e a tabela 1 e 2 mostra o fluxo de veículo estimado para cada movimento dos cruzamentos 1 e 5, respectivamente.
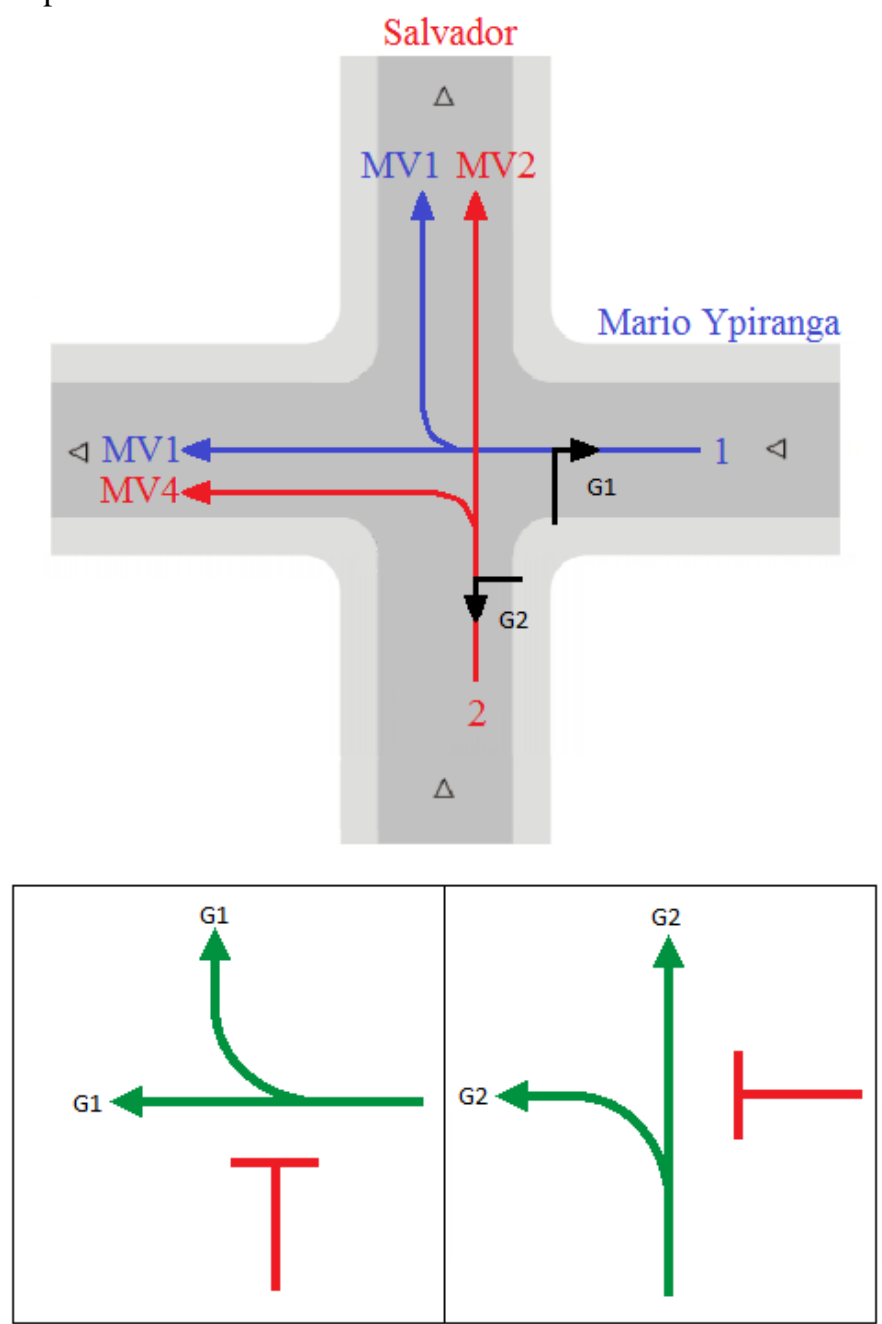

Estágio 1

Estágio 2

Figura 2: Diagrama de movimentos e estágios do cruzamento 1. Fonte: Autores, (2017).

Tabela 1: Fluxo de veículos estimado do cruzamento 1.

\begin{tabular}{|c|c|c|}
\hline Movimento & Hora-pico & Fluxo equivalente (por hora) \\
\hline $\mathbf{1}$ & $7: 30-8: 30$ & 3522 \\
\hline $\mathbf{2}$ & $7: 00-8: 00$ & 1961 \\
\hline $\mathbf{3}$ & $7: 30-8: 30$ & 463 \\
\hline $\mathbf{4}$ & $6: 30-7: 30$ & 1512 \\
\hline
\end{tabular}

Fonte: Autores, (2017).
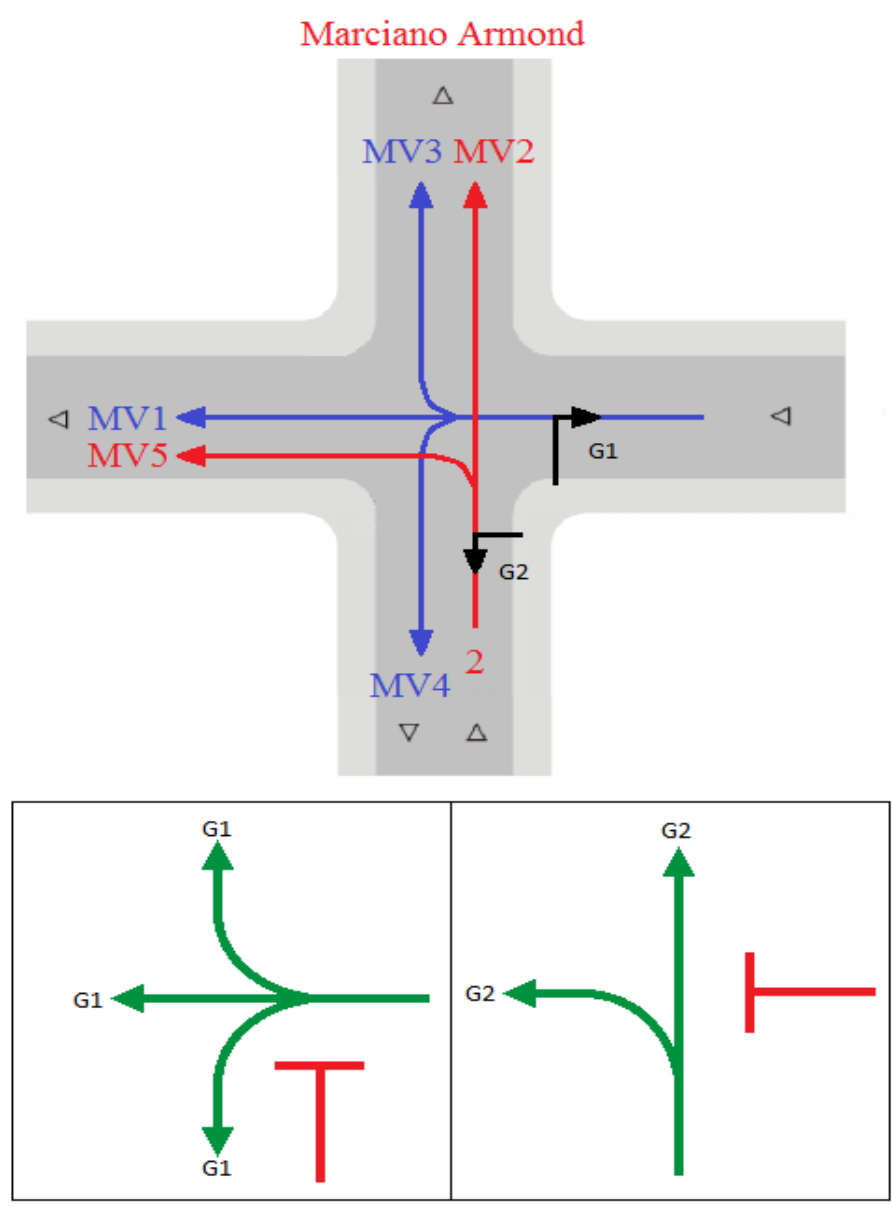

Estágio 1

Estágio 2

Figura 2: Diagrama de movimentos e estágios do cruzamento 5. Fonte: Autores, (2017).

Tabela 2: Fluxo de veículos estimado do cruzamento 5.

\begin{tabular}{|c|c|c|}
\hline Movimento & Hora-pico & Fluxo equivalente (por hora) \\
\hline $\mathbf{1}$ & $6: 30-7: 30$ & 682 \\
\hline $\mathbf{2}$ & $7: 00-8: 00$ & 550 \\
\hline $\mathbf{3}$ & $7: 15-8: 15$ & 1536 \\
\hline $\mathbf{4}$ & $6: 30-7: 30$ & 1429 \\
\hline $\mathbf{5}$ & $7: 15-8: 15$ & 103 \\
\hline
\end{tabular}

Fonte: Autores, (2017).

\section{III.2. SIMULAÇÃO}

Para melhor visualização do comportamento da malha e o tamanho da fila de veículos, foi desenhado no SUMO um trecho de $2,5 \mathrm{~km}$ que inclui os cinco cruzamentos semaforizados. A figura 4 demonstra como ficou a malha viária no simulador. $\mathrm{O}$ cruzamento 1 é o mais crítico devido a quantidade de veículos que passam nessa interseção, como mostrado na tabela 1 . Durante a simulação ocorreu a formação de grandes filas de veículos nas Avenidas Mario Ypiranga e Salvador antes do cruzamento 1, por este motivo serão mostrados nos resultados os dois trechos destacados em vermelho na figura 4 como forma de comparar o desempenho entre as diferentes formas de controle semafórico. 


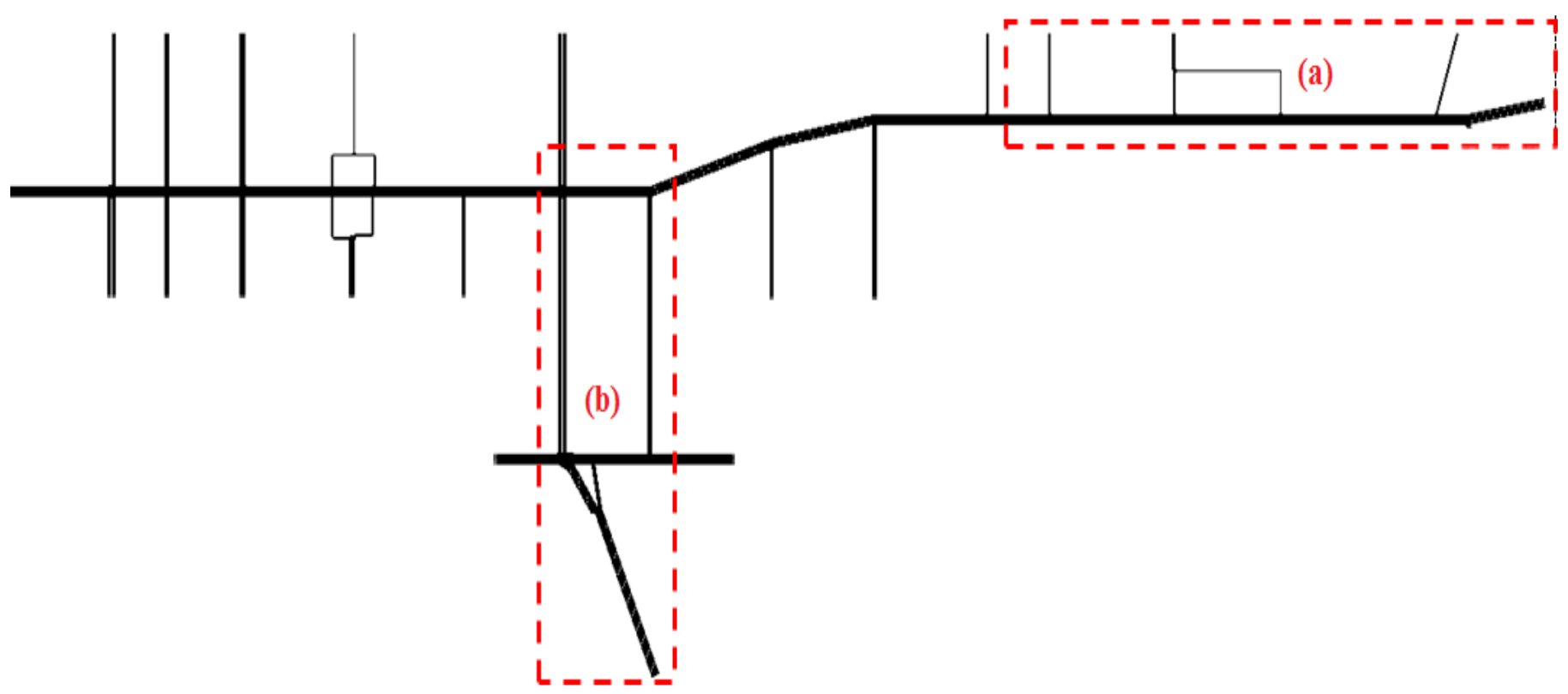

Figura 4: Malha viária no simulador: (a) - Trecho da Avenida Mario Ypiranga, (b) - Trecho da Avenida Salvador.

Fonte: Autores, (2017).

Foram feitas simulações para três situações possíveis: a primeira consiste na progressão semafórica proposta no projeto, a segunda e terceira são baseadas nos tempos levantados por [12] que corresponde a programação semafórica utilizada na via na época, mas, com mudanças nas defasagens e no tempo de verde do cruzamento 1, para também avaliar o impacto com a mudança de poucos segundos no tempo de verde. A tabela 3 apresenta os tempos utilizados nas simulações.

Tabela 3: Tempos e defasagens para a simulação da via atual.

\begin{tabular}{|c|c|c|c|c|c|c|c|}
\hline \multirow{2}{*}{ Cruzamento } & \multirow{2}{*}{ Via } & \multicolumn{2}{|c|}{ Progressão proposta } & \multicolumn{2}{|c|}{ Onda Verde 1} & \multicolumn{2}{|c|}{ Onda Verde 2} \\
\hline & & $\begin{array}{l}\text { Tempo de } \\
\text { verde (s) }\end{array}$ & $\begin{array}{l}\text { Defasagem } \\
\text { (s) }\end{array}$ & $\begin{array}{l}\text { Tempo de } \\
\text { verde (s) }\end{array}$ & $\begin{array}{c}\text { Defasagem } \\
\text { (s) }\end{array}$ & $\begin{array}{l}\text { Tempo de } \\
\text { verde (s) }\end{array}$ & $\begin{array}{l}\text { Defasagem } \\
\text { (s) }\end{array}$ \\
\hline \multirow{2}{*}{1} & Avenida Mario Ypiranga & 75 & \multirow[b]{2}{*}{0} & 43 & \multirow[b]{2}{*}{0} & 47 & \multirow[b]{2}{*}{0} \\
\hline & Rua Salvador & 82 & & 47 & & 43 & \\
\hline \multirow[t]{2}{*}{2} & Avenida Mario Ypiranga & 103 & \multirow{2}{*}{0} & 60 & \multirow{2}{*}{30} & 60 & \multirow{2}{*}{30} \\
\hline & Rua Fortaleza & 54 & & 30 & & 30 & \\
\hline \multirow[t]{2}{*}{3} & Avenida Mario Ypiranga & 112 & \multirow[t]{2}{*}{0} & 60 & \multirow[t]{2}{*}{40} & 60 & \multirow[t]{2}{*}{40} \\
\hline & Rua Terezina & 45 & & 30 & & 30 & \\
\hline \multirow{2}{*}{4} & Avenida Mario Ypiranga & 121 & \multirow[b]{2}{*}{0} & 60 & \multirow{2}{*}{49} & 60 & \multirow{2}{*}{49} \\
\hline & São Luiz & 36 & & 30 & & 30 & \\
\hline \multirow[t]{3}{*}{5} & Avenida Mario Ypiranga & 127 & \multirow[t]{2}{*}{0} & 60 & \multirow[t]{2}{*}{55} & 60 & \multirow[t]{2}{*}{55} \\
\hline & Rua Marciano Armond & 30 & & 30 & & 30 & \\
\hline & Tempo de Ciclo (s) & \multicolumn{2}{|c|}{167} & \multicolumn{2}{|c|}{100} & \multicolumn{2}{|c|}{100} \\
\hline
\end{tabular}

Fonte: Autores, (2017).

A velocidade de progressão para as três situações é de $55 \mathrm{~km} / \mathrm{h}$ ou $15,28 \mathrm{~m} / \mathrm{s}$, apesar de a avenida Mario Ypiranga ser uma via coletora, portanto velocidade máxima de $60 \mathrm{~km} / \mathrm{h}$, foi deixado uma margem de segurança para evitar que os condutores ultrapassem essa velocidade máxima. Para a progressão semafórica proposta, todos os 5 semáforos abrem na Avenida Mario Ypiranga no mesmo instante, mas o fechamento segue uma sequência de modo que os pelotões de veículos possam passar pelos cruzamentos sem parar. Os tempos foram calculados com base na distância entre cada cruzamento. Por último foram definidos os tempos de verde para a Mario Ypiranga no cruzamento 1 e para a Rua Marciano Armond, e todos os outros tempos de verde são calculados com base na defasagem. Além disso os tempos de amarelo e vermelho geral são de 3 e 2 segundos, respectivamente. A figura 5 mostra o diagrama de espaço-tempo para a progressão semafórica proposta, o tempo de ciclo é de 167 segundos e largura da banda é variável. A figura 6 mostra o diagrama de espaço-tempo para a onda verde 1, que possui banda de verde constante. 


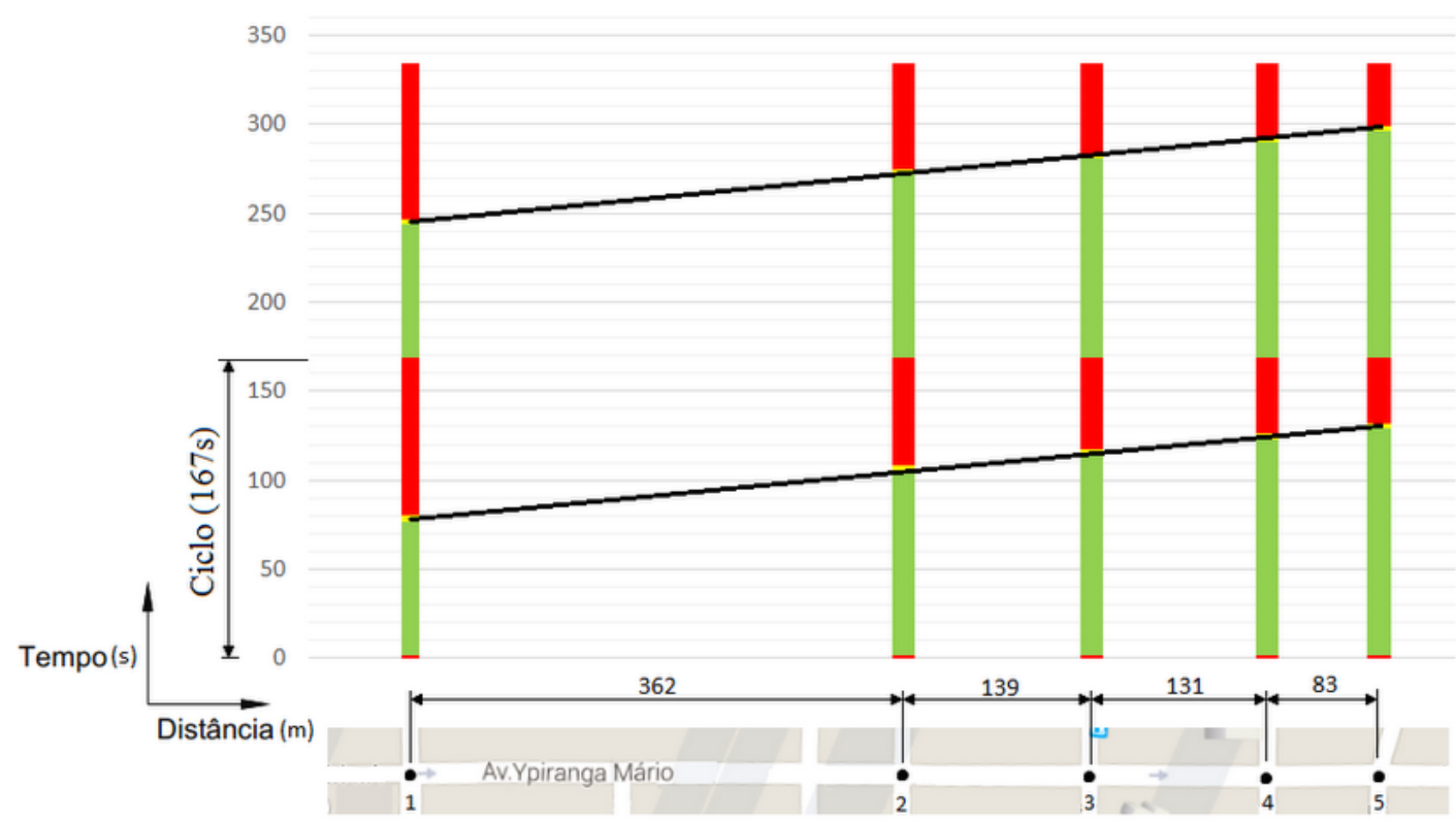

Figura 5: Diagrama espaço-tempo para a progressão semafórica proposta.

Fonte: Autores, (2017).

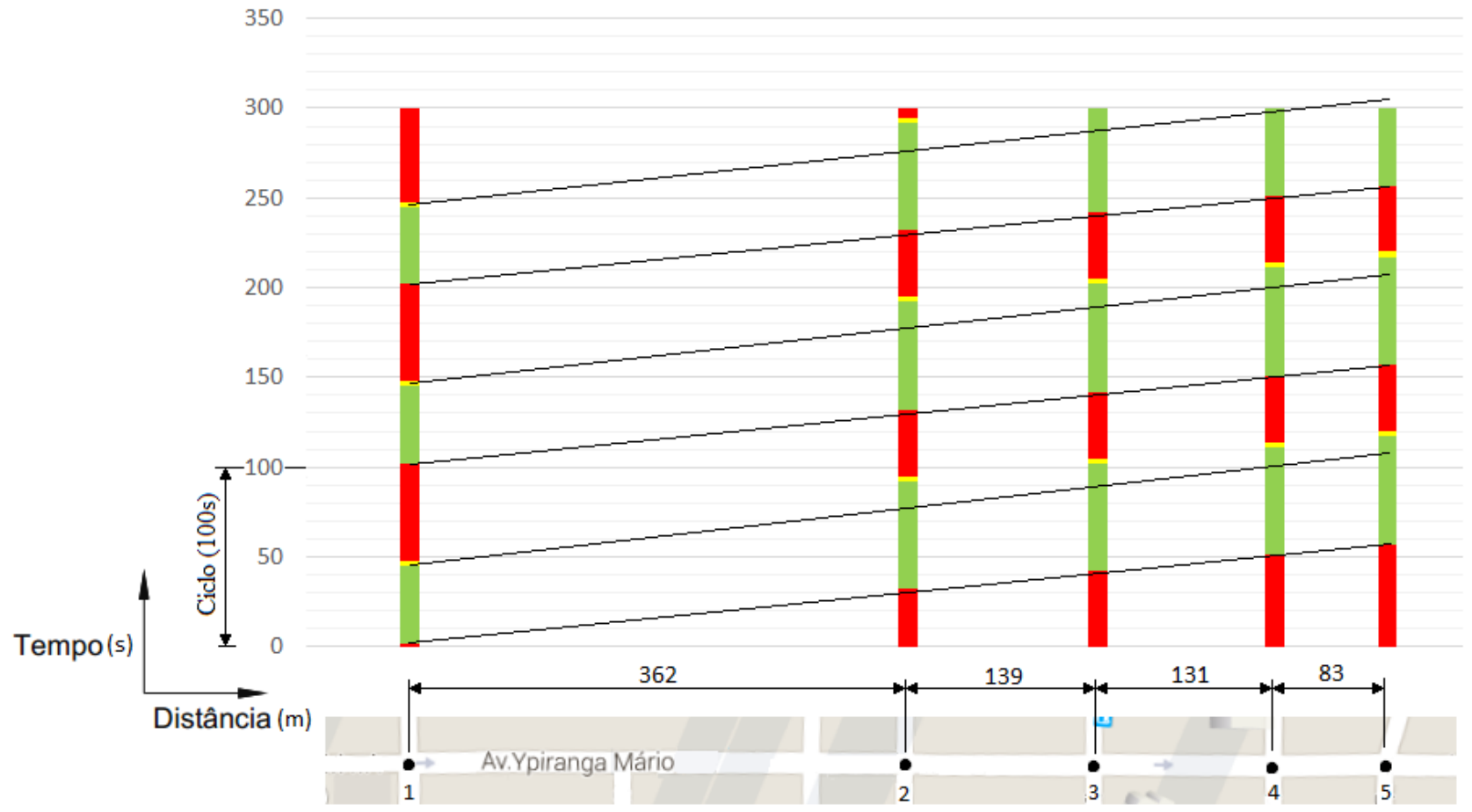

Figura 6: Diagrama espaço-tempo para a onda verde 1.

Fonte: Autores, (2017).

\section{RESULTADOS E DISCUSSÕES}

A simulação tem um total de 16 fluxos diferentes de veículos, mas somente os dados de dois serão analisados nos resultados, pois são os fluxos mais afetados pelo congestionamento: no primeiro os carros percorrem toda a extensão da Avenida Mario Ypiranga e no segundo percorrem a Avenida Salvador e no cruzamento 1 fazem a conversão na Avenida Mario Ypiranga e percorrem todo o restante dela. Desse modo serão analisados os impactos das 3 estratégias de coordenação nas duas principais vias da malha viária. 
Dias, Bastos \& Barbosa - ITEGAM-JETIA. Vol. 03, № 11, pp.22-30. Setembro, 2017.

A primeira forma de avaliar o desempenho das simulações feitas é por meio do tamanho das filas de veículos formadas. Para isso foi considerado o tempo de simulação de uma hora e as figuras 7 e 8 mostram o tamanho do congestionamento para as três estratégias na Avenida Mario Ypiranga (trecho A da figura 4) e na Avenida Salvador (trecho B da figura 4), respectivamente.
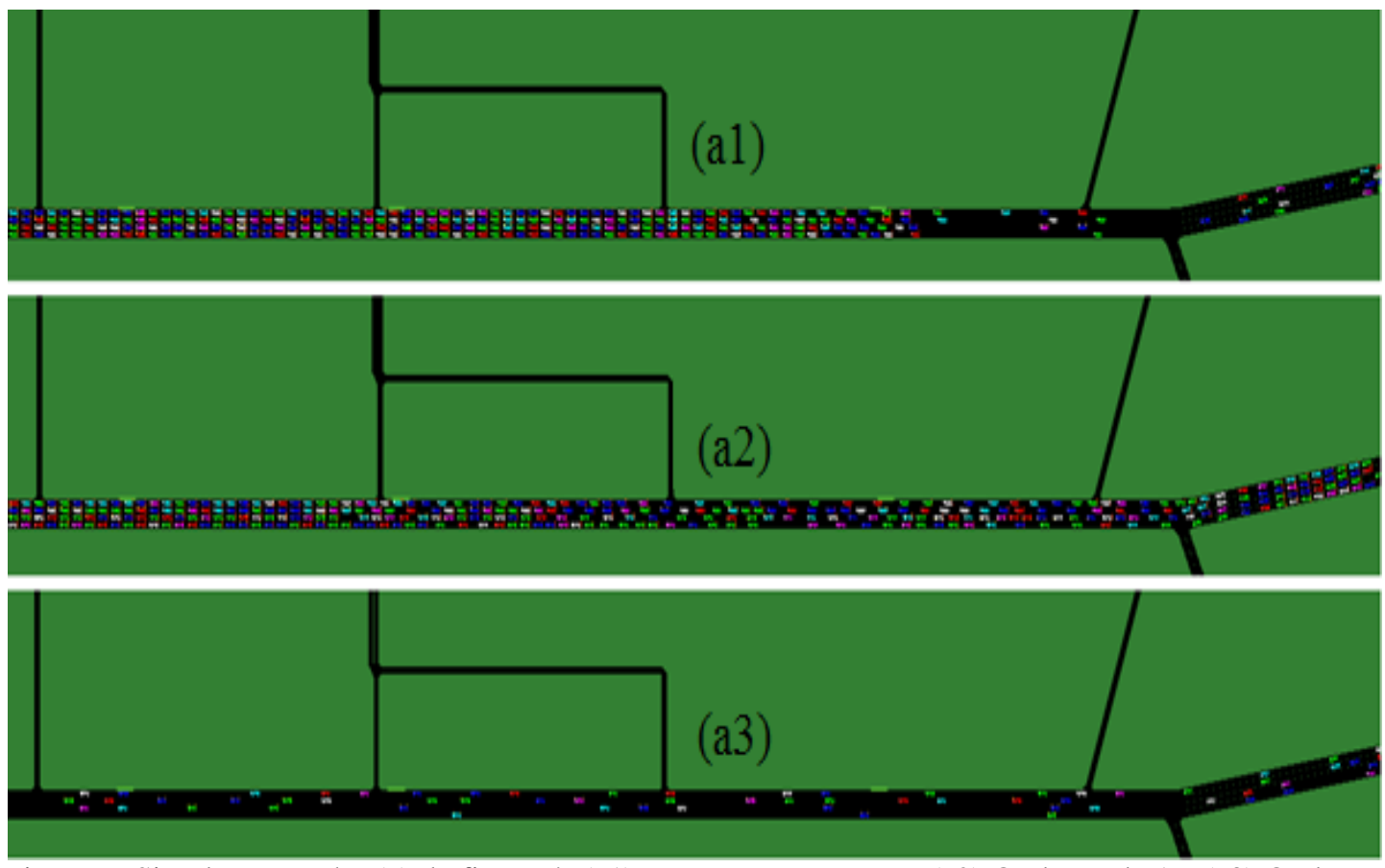

Figura 7: Simulação trecho (a) da figura 4: (a1) Progressão proposta, (a2) Onda verde 1 e (a3) Onda Verde 2. Fonte: Autores, (2017).
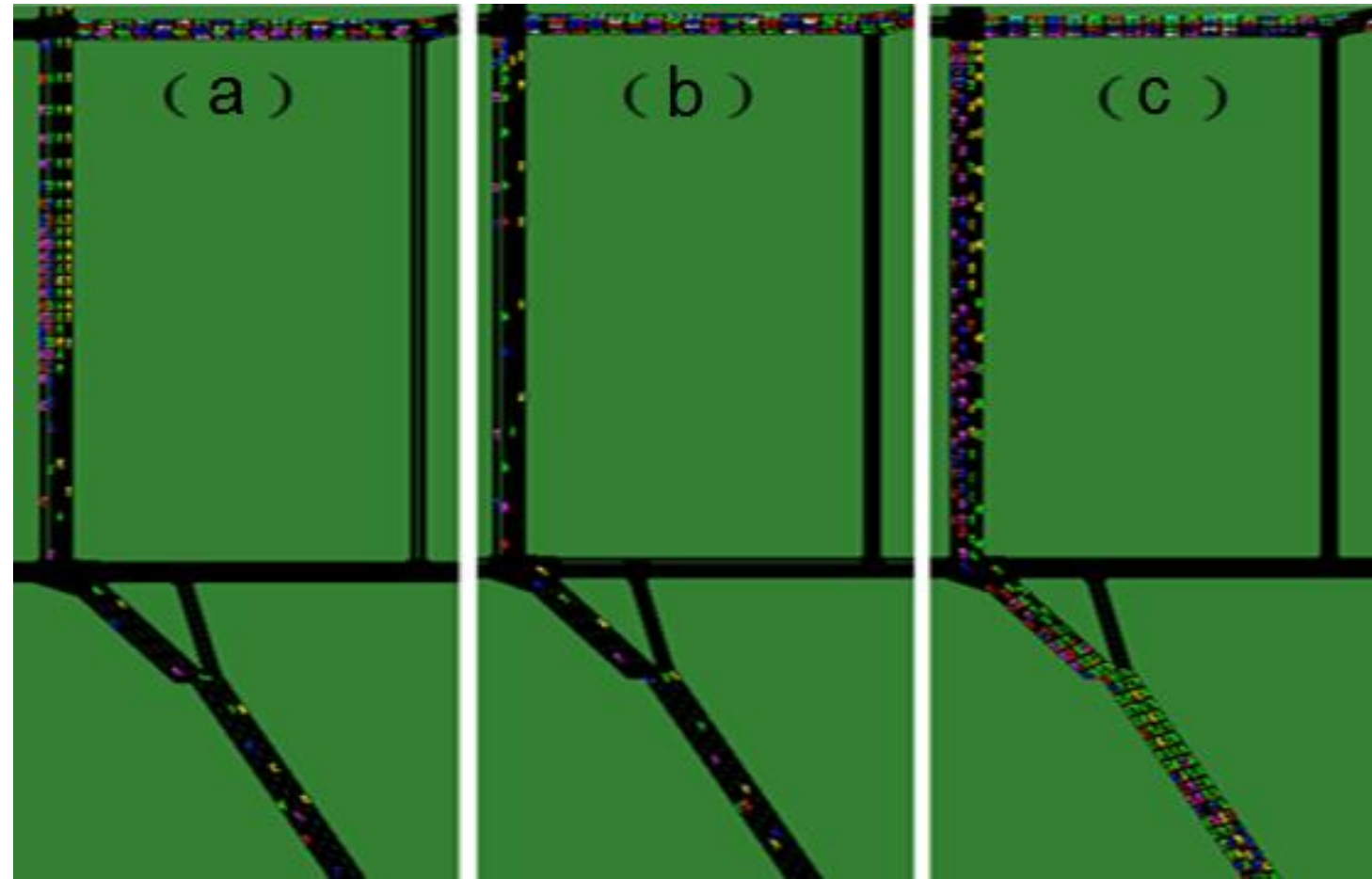

Figura 8: Simulação trecho (b) da figura 4: (a) Progressão proposta, (b) Onda verde 1 e (c) Onda Verde 2. Fonte: Autores, (2017).

O SUMO pode salvar em XML arquivos com inúmeros parâmetros referentes à simulação. Um desses arquivos, o tripinfo, que possui as informações da jornada de cada veículo gerado na simulação, foi exportado para uma planilha eletrônica e a partir da média dos veículos foram gerados dois gráficos. Os parâmetros usados para avaliar o desempenho da malha viária para cada situação foi o tempo de viagem, o tempo parado e o tempo perdido de todos os carros do fluxo 1 e do fluxo 2 que percorreram a malha viária durante uma hora, mostrados na figura 9. Além disso, foi calculado a velocidade média para cada situação que é mostrado na figura 10. 
Dias, Bastos \& Barbosa - ITEGAM-JETIA. Vol. 03, № 11, pp.22-30. Setembro, 2017.

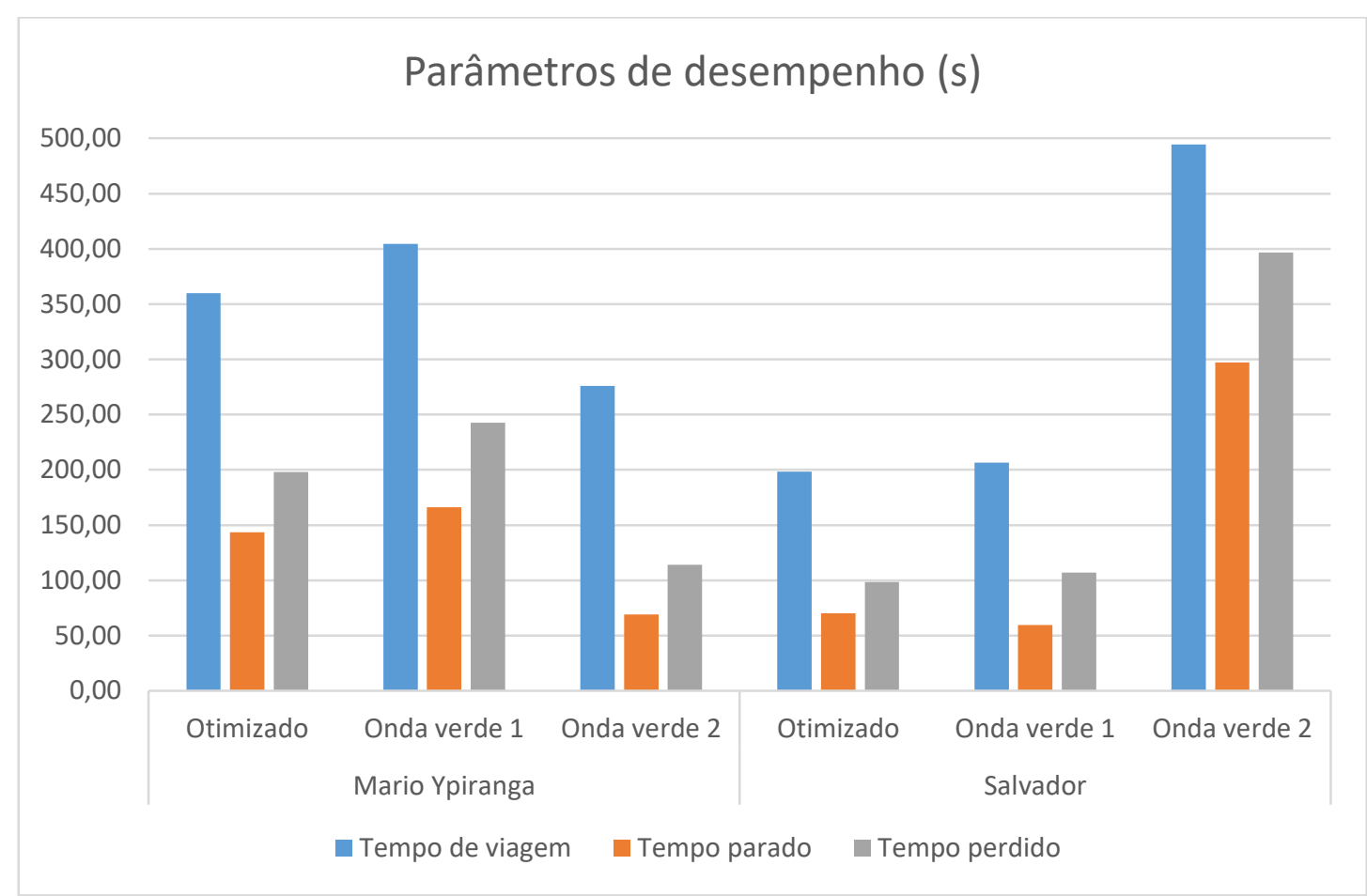

Figura 9: Gráfico com os parâmetros de desempenho.

Fonte: Autores, (2017).

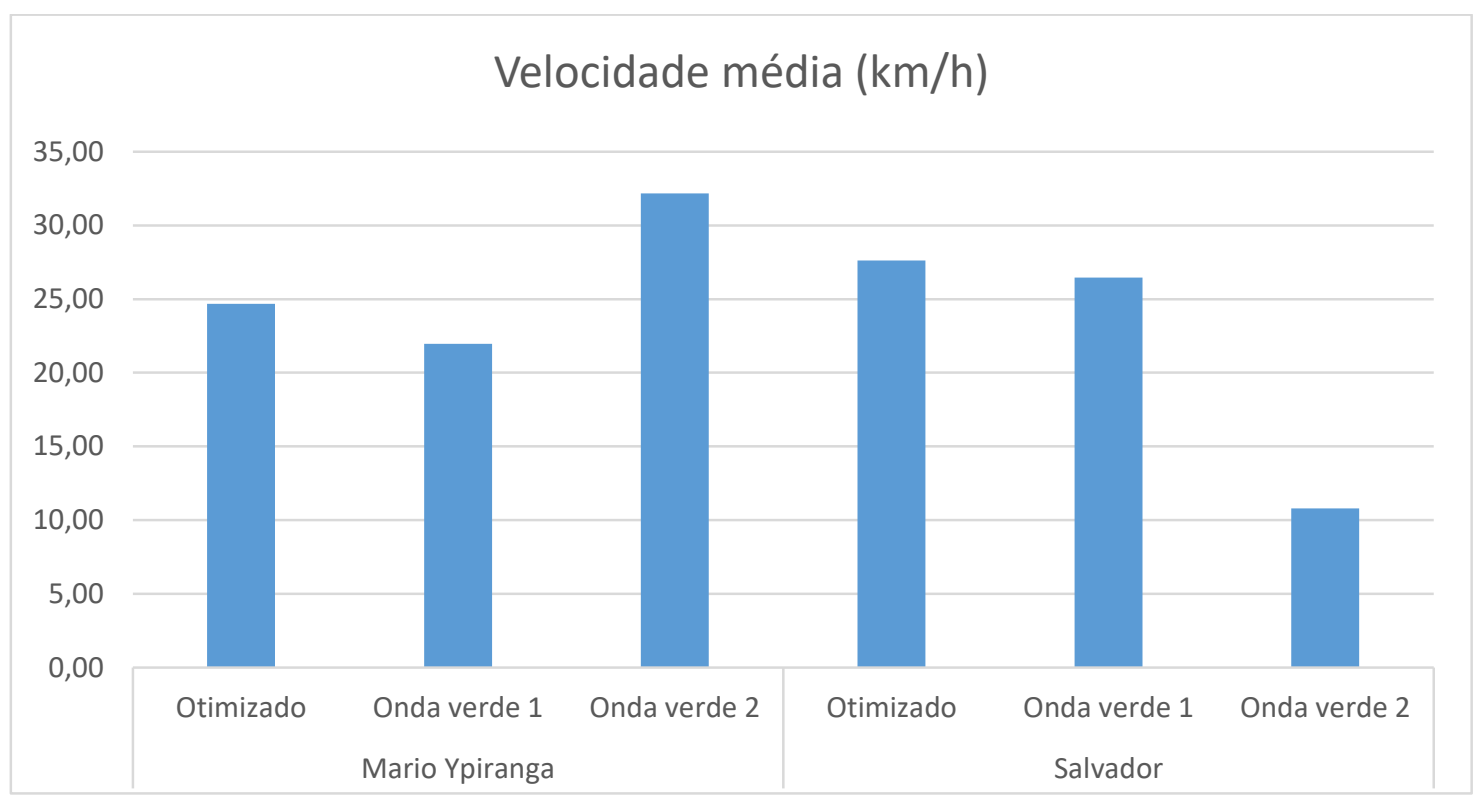

Figura 10: Gráfico da velocidade média dos veículos.

Fonte: Autores, (2017).

\section{CONCLUSÃO}

Este trabalho possibilitou avaliar o desempenho da proposta de implantação de progressão semafórica flexível para a Avenida Mario Ypiranga Monteiro na cidade de Manaus, que tem como objetivo reduzir o congestionamento naquela via que possui grande importância para a deslocamento urbano. A progressão flexível obteve melhor desempenho do que as onda verdes pois pode reduzir o tempo de viagem, o tempo parado e o tempo perdido de acordo com a figura 9 além de aumentar a velocidade média nas vias. $\mathrm{Na}$ onda verde 2 pode-se notar um desempenho bem superior na avenida Mario Ypiranga, mas com uma retenção bastante elevada na avenida Salvador como mostra a figura $8 \mathrm{c}$.

Ao longo da simulação pode-se perceber que a defasagem positiva presente nas duas ondas verdes não desempenhou um bom papel no momento da abertura dos semáforos da avenida Mario Ypiranga pois o pelotão de um cruzamento começava a andar e em seguida encontrava uma fila de veículos parados no próximo cruzamento, dificultando o fluxo de veículos. $\mathrm{Na}$ progressão semafórica flexível os cinco cruzamentos abrem simultaneamente de modo que o tempo que 
um pelotão leva para chegar no próximo cruzamento seja o suficiente para que a fila de veículos parados já esteja se movendo, o que possibilita reduzir o consumo de combustível e o desgaste do sistema de frenagem dos veículos, além de reduzir o tempo de viagem e o tempo perdido que por consequência diminui o estresse dos condutores e passageiros que transitam na via e reduz o impacto ambiental, o que contribui para a melhora da qualidade de vida da população.

\section{AGRADECIMENTOS}

Os autores agradecem à MANAUSTRANS por fornecer os dados necessários para o projeto e à Universidade do Estado do Amazonas - UEA junto com a FAPEAM que por meio do Programa de Apoio a Iniciação Científica permite os alunos desenvolverem projetos de pesquisa.

\section{REFERÊNCIAS}

[1]. Cruz, W. UNIVERSIDADE PRESBITERIANA MACKENZIE, Faculdade de Computação e Informática. Aplicação de Algoritmos Genéticos em Semáforos Inteligentes. Universidade Presbiteriana Mackenzie, 2011. 115p, il. Trabalho de conclusão de curso.

[2]. GOVERNO DO AMAZONAS. Custo com congestionamento em Manaus é de $\mathbf{R} \$ 530$ milhões/ano. Manaus, 23 maio 2011. Disponível em: <http://www.amazonas.am.gov.br/2011/05/custo-comcongestionamento-em-manaus-der-530-milhesano/>. Acesso em: 5 de junho de 2016.

[3]. Cybis, H. B. B.; Lindau, L. A.; Araujo, D. R. C. Implantação de um modelo de simulação e alocação de tráfego em Porto Alegre. Revista dos Transportes Públicos ANTP, São Paulo, v.1, n.95, p. 41-54, 2002.

[4]. DENATRAN - Departamento Nacional de Trânsito. Manual Brasileiro de Sinalização de Trânsito Volume V- Sinalização Semafórica. $3^{a}$ Edição. Brasília: DENATRAN, 2012.

[5]. Dutra, C. B.; DemarchiI, S. H. Coordenação semafórica através do método de maximização da banda de verde. Anais: XVIII Congresso Brasileiro de Transporte e Trânsito, Florianópolis: ANTP, 2004.

[6]. Webster, F. V.; Cobre, B. M. Traffic Signals: Road Reseacher Technical Paper. Road Research Laboratory Ministry of Transport, London, England, n.56, 1966.

[7]. Roess, R. P.; Mc Shane, W. R.; Prassas, E. S. Traffic Engineering. Prentice Hall, New Jersey, Second Edition, 1998.

[8]. Almeida, A. F. M.; Meneses, H. B. Avaliação da progressão semafórica em tempo real nos períodos de média e alta demanda de tráfego: Estudo de caso. Anais: XVI Congresso Brasileiro de Transporte e Trânsito, Maceió: ANTP, 2007.
[9]. Lopes, L C. F. UNIVERSIDADE FEDERAL DO RIO DE JANEIRO, COPPE. Método de Otimização das Defasagens de Corredores, 2010. 140p, il. Dissertação (Mestrado).

[10]. Dutra, C. B. Avaliação da eficiência de métodos de coordenação semafórica em vias arteriais. Universidade de São Paulo. Escola de Engenharia de São Carlos. Departamento de Transportes, 2005. 203p. Dissertação (Mestrado).

[11]. Hallmann, H. V. UNIVERSIDADE FEDERAL DO RIO GRADNE DO SUL, Instituto de Informática. Comparação entre softwares Simuladores de Trânsito. Universidade Federal do Rio Grande do Sul, 2011. 104p, il. Trabalho de conclusão de curso.

[12]. Oliveira, W. D. T. Proposta de semáforos inteligentes usando estratégias de controle TUC para um conjunto de cruzamentos subsequentes da cidade de Manaus. Universidade do Estado do Amazonas, 2014. 